\title{
Particularities of phase transitions in thermomechanically processed Cu-Al-Mn shape memory alloys
}

\author{
S. Stanciu, L. G. Bujoreanu', R. I. Comăneci, N. Cimpoeşu, I. Ioniţă, V. V. Moldoveanu
}

Faculty of Materials Science and Engineering, The "Gh. Asachi" Technical University from Iaşi, Bd. D. Mangeron 61A, 700050 Iaşi. Romania

\begin{abstract}
The thermally and stress induced phase transitions occurring in a Cu-Al-Mn Shape Memory Alloy (SMA) have been investigated by means of thermal analysis techniques, tensile testing and microscopic observations. On heating a hot rolled solution annealed $\mathrm{Cu}-\mathrm{Al}-\mathrm{Mn} \mathrm{SMA}$, up to $873 \mathrm{~K}$, two phase transformations, related to equilibrium phase precipitation and to 2-step order-disorder transition, respectively, were revealed by Differential Scanning Calorimetry (DSC). During tensile testing, the Cu-Al-Mn SMA under study experienced almost complete superelasticity, after five mechanical training cycles, as well as good ductility and tensile resistance. On trained specimens the formation of stress induced martensite was revealed by optical microscopy (OM) observations. The reversion to austenite of stress induced martensite was accompanied by relatively large increases of elastic modulus and internal friction, determined on Dynamic Mechanical Analyzer (DMA) and by marked variations of relative elongation, thermal expansion coefficient and elongation rate, determined by dilatometry. Since it is a two step transition, it was associated with the two morphologies of stress induced martensite observed by Scanning Electron Microscopy (SEM).
\end{abstract}

\section{Introduction}

The development of $\mathrm{Cu}-\mathrm{Al}-\mathrm{Ni}$ shape memory alloys (SMAs) started in 1957 [1] and evolved during more than half a century up to Mn-containing quaternary modifications, grain refined with $\mathrm{B}, \mathrm{Ce}, \mathrm{Co}, \mathrm{Fe}, \mathrm{Ti}, \mathrm{V}$, and $\mathrm{Zr}$ [2]. Presently it is considered that this alloy system has become commercially available due to its relatively low cost and thermoelastic character of martensitic transformation [3], being 50 to 100 times less expensive than Ni-Ti as compared to which it is preferred to for some high temperature applications such as clamps or fire detectors [4].

When substituting $\mathrm{Ni}$ by $\mathrm{Mn}$, a marked broadening of the region of $\beta$-phase (commonly called austenite) occurs, accompanied by a two step disorder $\rightarrow$ order transition, $\beta(\mathrm{A} 2) \rightarrow \beta_{2}(\mathrm{~B} 2) \rightarrow \beta_{1}\left(\mathrm{~L} 2_{1}\right)$ [5]. The formation of ordered $\beta_{1}$ austenite with $\mathrm{Cu}_{2} \mathrm{MnAl}$ stoichiometric formula induces ferromagnetic character [6] even it occurs under the form of ordered nanoparticles in a paramagnetic matrix [7]. When ordered austenite ( $\beta_{1}$ based on $\left.\mathrm{Cu}_{3} \mathrm{Al}\right)$ is slowly cooled, it decomposes into a eutectoid [8] $\alpha(\mathrm{Cu}$-based, fcc $)+\gamma_{2}$, based on $\left.\mathrm{Cu}_{9} \mathrm{Al}_{4}\right)$ but when it is rapidly cooled a martensitic transition occurs, up to four martensites $\left(\alpha^{\prime}{ }_{1}, \beta^{\prime}{ }_{1}, \beta^{\prime}{ }_{1}\right.$ and $\left.\gamma_{1}{ }_{1}\right)$ being formed [9].

In previous reports the influence of $\gamma_{2}$ phase precipitation on shape memory behaviour of $\mathrm{Cu}-\mathrm{Al}-\mathrm{Ni}-\mathrm{Mn}-\mathrm{Fe}$ SMAs was analyzed and no major changes were detected in the subsequent reversion of martensite to austenite, after the quenching of an alloy in which hard $\gamma_{2}$-phase had precipitated [10]. Moreover, no orientation relationship was revealed between austenitic matrix and precipitates although the alloy under study experienced shape recovery degrees higher than $96 \%$ [11]. Another study, performed by some of the present authors on a $\mathrm{Cu}-\mathrm{Al}-\mathrm{Mn}$ SMA in austenitic condition, allowed observing by Differential Scanning Calorimetry (DSC) two solid state transitions, during heating: (i) an exothermic precipitation of equilibrium $\alpha$-phase and (ii) an endothermic two step transformation of ordered $\beta_{1}\left(\mathrm{~L} 2_{1}\right)$ austenite, firstly into less ordered $\beta_{2}$ (B2) austenite and then into completely disordered $\beta$ (A2) austenite [12]. This suggested that solution annealed Cu-Al-Mn SMA experienced similar behaviour to $\mathrm{Ni}-\mathrm{Ti}$ alloys since no thermally induced martensite was formed after water cooling, however the presence of thermal memory has yet to be substantiated.

Therefore, the present study aims: (i) to emphasize the formation of stress induced martensite in an austenitic $\mathrm{Cu}-\mathrm{Al}$-Mn SMA, plastically deformed as an effect of mechanical training; (ii) to demonstrate the thermally induced reversion to austenite of the stress induced martensite which formed as an effect of training and (iii) to reveal some particular aspect of the morphology and heating behaviour of stress induced martensite.

\footnotetext{
a e-mail: Igbujor@tuiasi.ro
}

This is an Open Access article distributed under the terms of the Creative Commons Attribution-Noncommercial License (http://creativecommons.org/licenses/by-nc/3.0/), which permits unrestricted use, distribution, and reproduction in any noncommercial medium, provided the original work is properly cited. 


\section{Experimental procedure}

A Cu-9.23 Al-5.3 Mn-0.6 Fe (mass, \%) SMA was obtained by casting, hot rolling (973 K) and homogenization annealing (1173 K/ 8.3.6 ksec/ air). Specimens were prepared from for Differential Scanning Calorimetry (DSC), tensile tests (TENS), Optical Microscopy (OM), Dynamic Mechanical Analyzer (DMA), dilatometry (DIL) and scanning electron microscopy (SEM), respectively.

DSC measurements were performed on a NETZSCH STA 449 F3 device during a heating-cooling cycle between RT and $870 \mathrm{~K}$, under Ar atmosphere, at a rate of $1.66 \times 10^{-1} \mathrm{~K} / \mathrm{s}$. TENS experiments were performed on an INSTRON 3382 tensile testing machine with a deformation rate of $2.77 \times 10^{-4} \mathrm{sec}^{-1}$, using an extensometer. OM observations were conducted on a MEJI microscope using specimens etched with $30 \% \mathrm{HNO}_{3}$ solution in ethanol. A NETZSCH DMA 242 device, functioning in 3 point bending mode at a frequency of $1 \mathrm{~Hz}$ and an amplitude of $20 \times 10^{-6} \mathrm{~m}$, was used in order to determine the variations of internal friction (Tan $\Phi$ ) and elastic modulus (E) during heating, with a rate of $5 \times 10^{-2} \mathrm{~K} / \mathrm{s}$ from RT to $620 \mathrm{~K}$. DIL measurements were performed on a NETZSCH DIL $402 \mathrm{CD}$ dilatometer, in previously mentioned conditions [13], allowing to record the variation with temperature of the relative elongation $\left(\mathrm{dL} / \mathrm{L}_{0}\right)$, expansion rate $\mathrm{d}\left(\mathrm{dL} / \mathrm{L}_{0}\right) / \mathrm{dt}$ and thermal expansion coefficient $(\alpha)$. SEM analysis was conducted on etched specimens on a SEM - VEGA II LSH TESCAN scanning electron microscope, coupled with an EDX - QUANTAX QX2 ROENTEC detector.

\section{Experimental results and discussion}

\subsection{Thermally induced phase transitions}

The typical DSC thermogram of a fragment cut from a hot rolled solution annealed specimen, during a heatingcooling-heating cycle, is illustrated in Fig. 1.

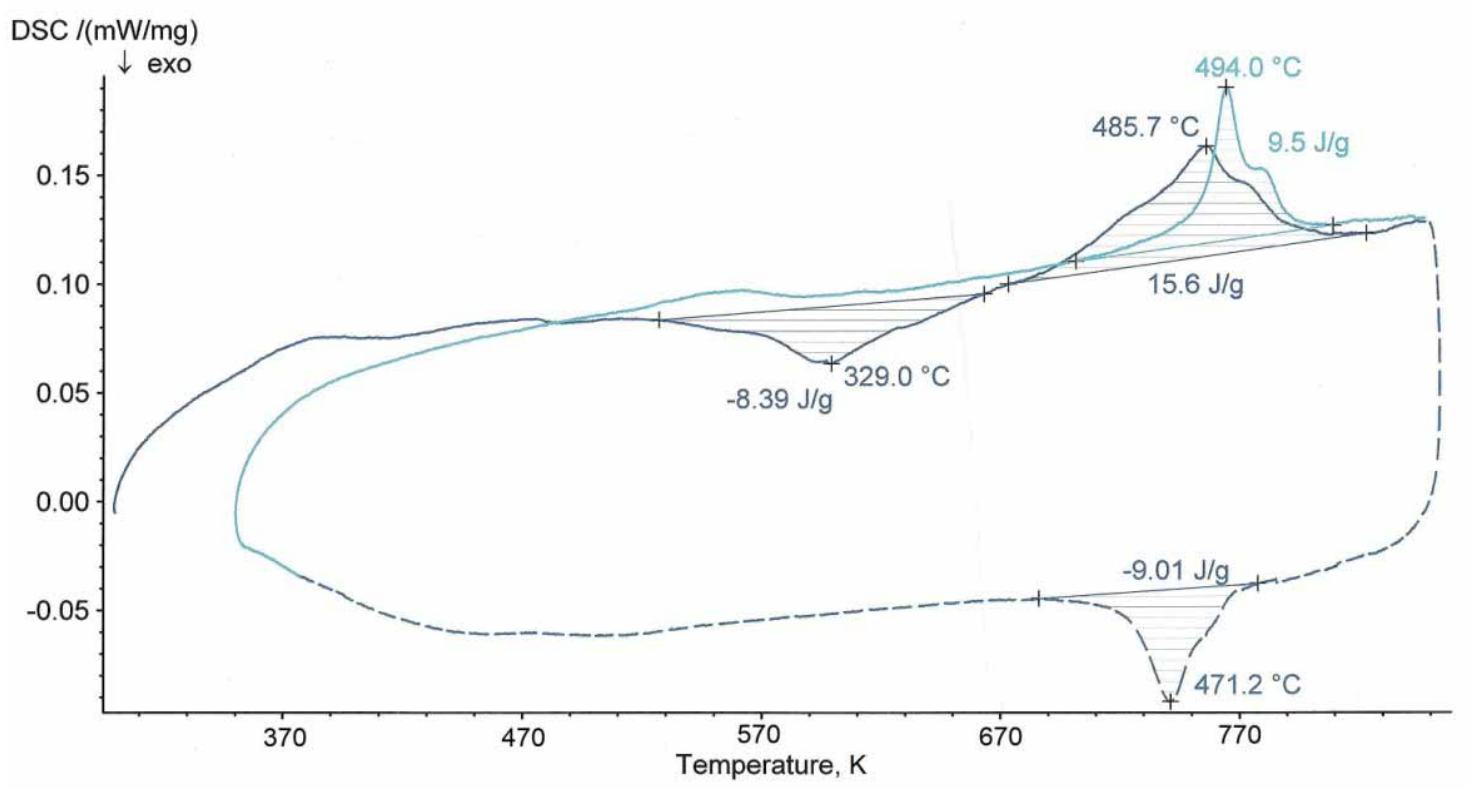

Fig.1 Typical DSC thermogram of a fragment cut from a hot rolled solution annealed Cu-9.23 Al-5.3 Mn-0.6 Fe (mass, \%) SMA recorded during a heating-cooling-heating

In accordance to our previous report [12], two phase transformations are noticeable during heating, which could be associated with the exothermic precipitation, at $600 \mathrm{~K}$, of equilibrium $\alpha$ phase [14] and with the endothermic order-disorder transition, at $756 \mathrm{~K}$, of austenite, respectively [15]. During cooling, a two step disorder-order transition becomes noticeable, being located at $741 \mathrm{~K}$.

Considering that cooling was interrupted at room temperature (RT), it may be assumed that direct martensitic transformation did not occur, since critical temperature $\mathrm{M}_{\mathrm{s}}$ would be located in cryogenic domain, as an effect of water quenching, being additionally depressed by Fe addition [16]. For this reason it is assumed that, during first heating, the amount of $\mathrm{Cu}$-rich $\alpha$ phase increased thus removing $\mathrm{Cu}$ from the matrix which subsequently experienced an order-disorder transition. During cooling, only the two-step ordering transition of austenite occurs which doesn't experience any other transformation. $\mathrm{Cu}$ depleted ordered austenite cannot further enhance $\alpha$ phase formation, during second heating, and two-step order-disorder transition occurs at $764 \mathrm{~K}$, at slightly higher temperatures, as compared to first heating. 
Considering there was no evidence of the formation of thermally induced martensite, as an effect of water cooling comprised in the solution annealing heat treatment, it is assumed that the specimens are in austenitic domain, which would enhance the presence of superelasticity.

\subsection{Stress induced phase transitions}

The tensile behaviour of solution annealed specimens is summarized in Fig. 2.
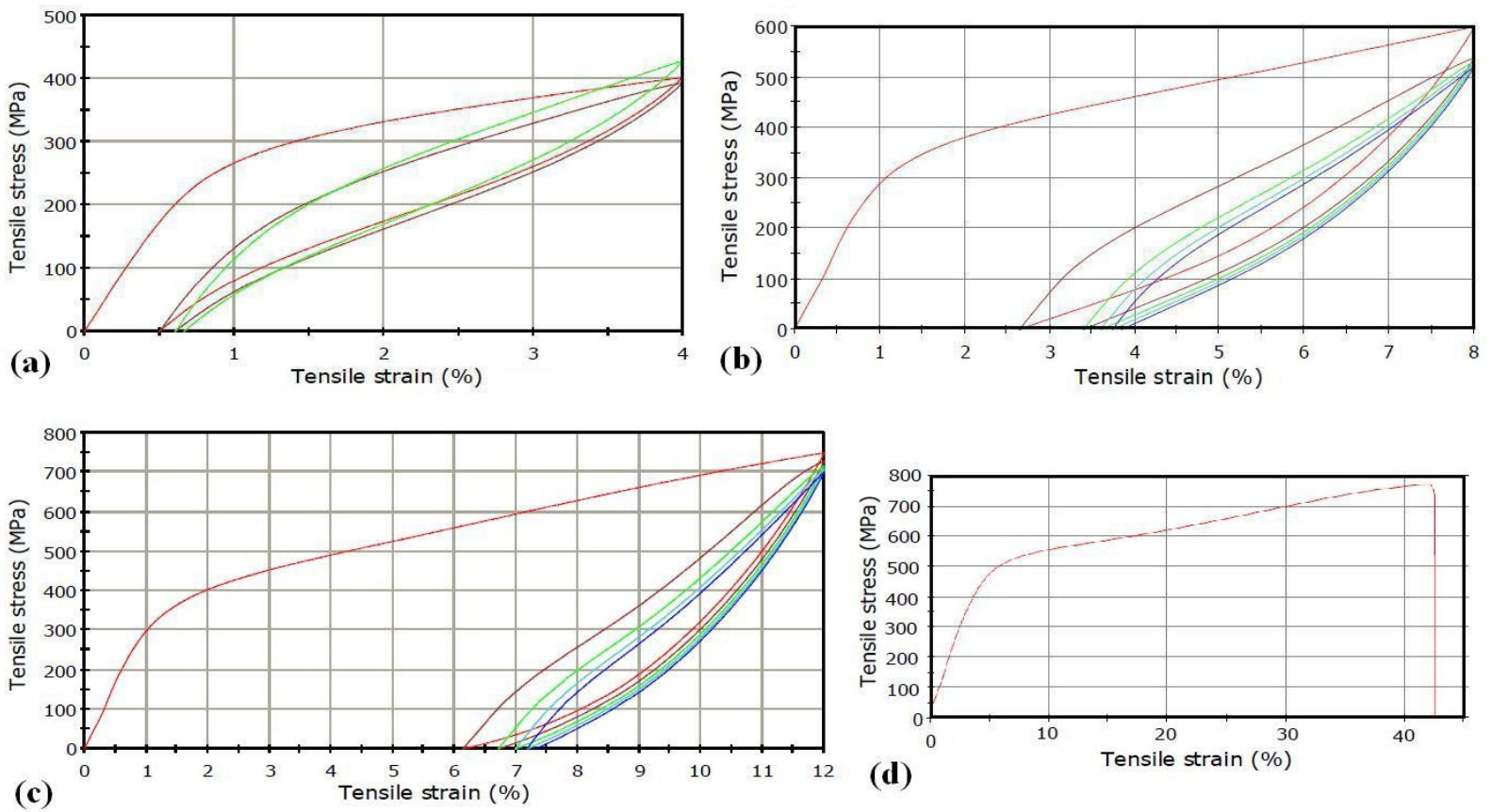

Fig. 2 Summary of tensile behaviour of hot rolled solution annealed Cu-9.23 Al-5.3 Mn-0.6 Fe (mass, \%) SMA: (a) three mechanical training cycles up to $4 \%$ maximum strain; (b) five mechanical training cycles up to $8 \%$ maximum strain; (c) five mechanical training cycles up to $12 \%$ maximum strain; (d) tensile stress-strain failure curve;

It is noticeable from Fig. 2(a-c) that the specimens experienced superelastic behaviours, characterized by stress plateaus, both on loading and unloading, which accompany reversible stress induced martensitic transformations. Moreover, with increasing the number of training cycles, the loading-unloading loops tend to close, yet they have different shapes in Fig. 2(a) as compared to Fig. 2(b) and (c), probably due to the intervention of slip, as a plastic deformation mechanism. Finally Fig. 2(d) shows the tensile failure curve of the alloy under study revealing an ultimate strain above $40 \%$ and a tensile strength of almost $800 \mathrm{MPa}$. In order to reveal training effects on the superelastic behaviour, Table 1 lists the values of recoverable and remanent strains corresponding to Figs. 2(a-c).

Table 1. Values of recoverable and remanent strains (in brackets) corresponding to the mechanical training cycles of Fig. $2(\mathrm{a}-\mathrm{c})$, as a function of maximum strain; \%

\begin{tabular}{|c|c|c|c|c|c|}
\hline \multirow{2}{*}{$\begin{array}{c}\text { Maximum } \\
\text { strain, } \%\end{array}$} & \multicolumn{5}{|c|}{ No of cycle } \\
\cline { 2 - 6 } & 1 & 2 & 3 & 4 & 5 \\
\hline 4 & $3.5(0.5)$ & $3.39(0.11)$ & $3.33(0.06)$ & - & - \\
\hline 8 & $5.32(2.68)$ & $4.57(0.75)$ & $4.34(0.23)$ & $4.21(0.13)$ & $4.1(0.11)$ \\
\hline 12 & $5.83(6.17)$ & $5.23(0.6)$ & $4.99(0.24)$ & $4.78(0.21)$ & $4.64(0.14)$ \\
\hline
\end{tabular}

It follows that after 5 training cycles, recoverable strains larger than $4 \%$ were obtained with remanent strains lower than $0.15 \%$. These values suggest that, after mechanical training, almost perfect superelasticity has been obtained but the specimen remained elongated and the formation of stress-induced martensite can be assumed. One of the possible ways to prove the formation of stress induced martensite is to observe the same area of a polished specimen both before and after plastic deformation. In such cases a specific structural detail is chosen in order to allow the identification of the same area, after plastic deformation. Such an example is given in Fig. 3, which shows the optical micrographs of the same area of a polished specimen, in initial (unelongated) condition and elongated with $7.36 \%$, after 5 mechanical training cycles, as illustrated in Fig. 2(c). 

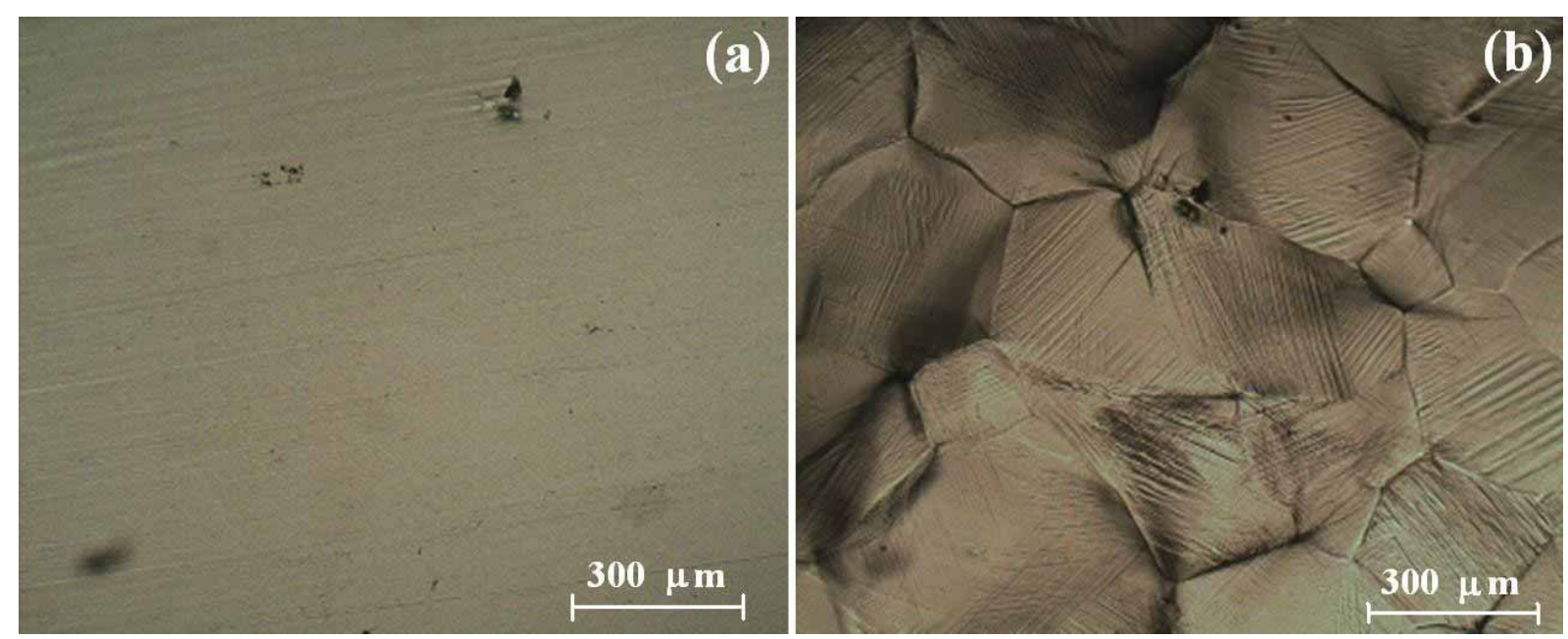

Fig. 3 Optical micrographs of polished specimens of hot rolled solution annealed Cu-9.23 Al-5.3 Mn-0.6 Fe (mass, \%) SMA: (a) in initial state; (b) after 5 mechanical training cycles up to $12 \%$ total strain, with a cumulative permanent strain of $7.36 \%$

Stress induced martensite plates are noticeable in Fig. 3(b) and most of them completely crossed austenite grains, generally under the form of plates belonging to a single martensite variant. Aiming to observe how this stress induced martensite would behave during heating, DMA and DIL observations were performed. The results are shown in Figs. 4 and 5, respectively.

Fig. 4 illustrates a typical record of DMA measurements, illustrating the variation with temperature, on heating, of internal friction (Tan $\Phi$ ) and elastic modulus (E).

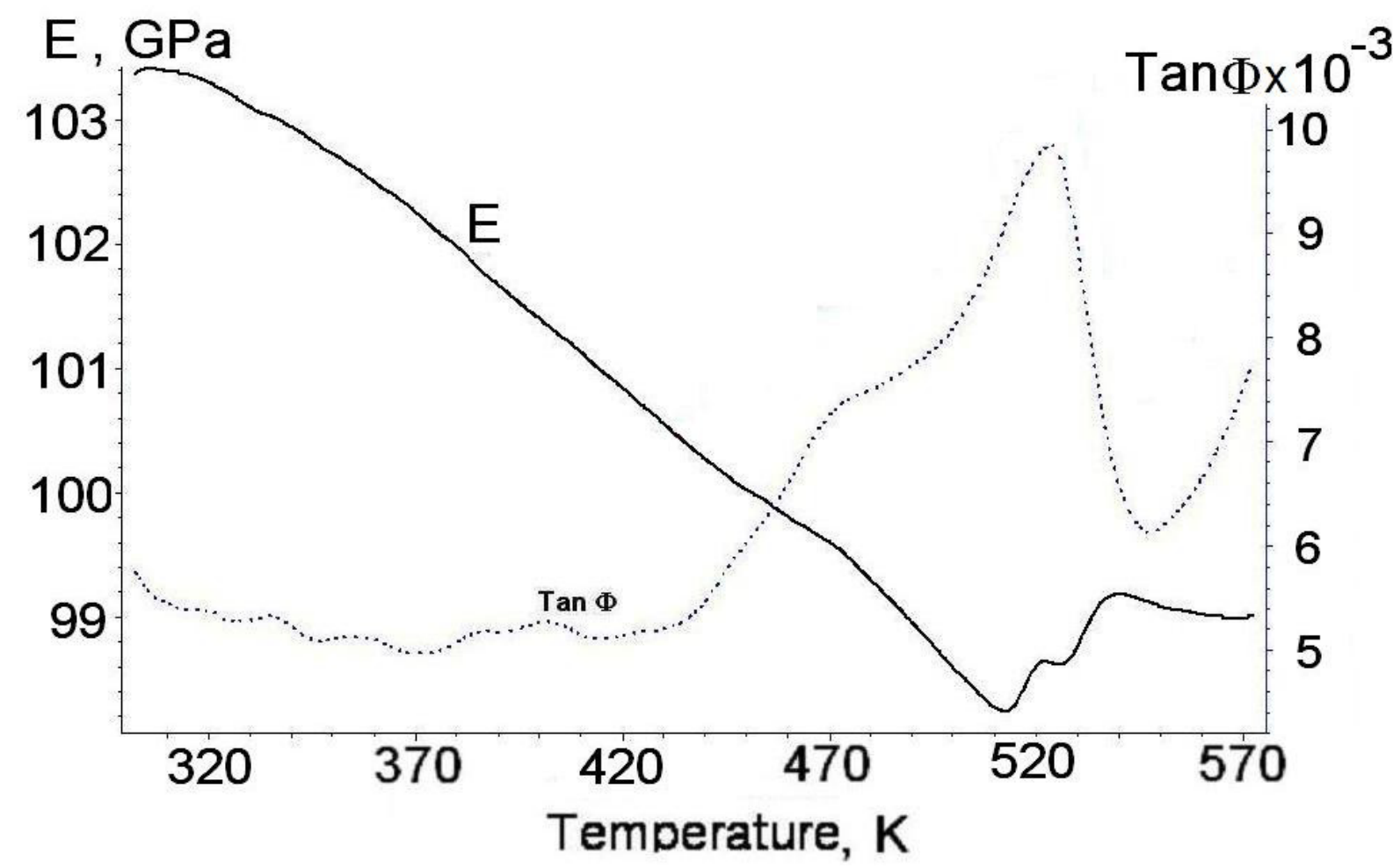

Fig. 4 Variations with temperature, of internal friction (Tan $\Phi)$ and elastic modulus (E), during the heating of a strained specimen of hot rolled solution annealed Cu-9.23 Al-5.3 Mn-0.6 Fe (mass, \%) SMA trained by 5 mechanical cycles up to 12 $\%$

The variation of elastic modulus suggests the presence of two partially overlapping phase transitions. The former is accompanied by a slight and graduate increase between about 440 and $470 \mathrm{~K}$ while the latter is revealed by a marked modulus increase, with approx. $1 \mathrm{GPa}$, between 510 and $540 \mathrm{~K}$. These transitions are accompanied by internal; friction increases, up to about 0.007 , for the first one and up to 0.01 for the second one. For a better insight on the solid state transition occurring in elongated $\mathrm{Cu}-9.23 \mathrm{Al}-5.3 \mathrm{Mn}-0.6 \mathrm{Fe}$ specimens, as an effect of mechanical training, the variations with temperature of relative elongation $\left(\mathrm{dL} / \mathrm{L}_{0}\right)$, of expansion 
rate $\left(\mathrm{d}\left(\mathrm{dL} / \mathrm{L}_{0}\right) / \mathrm{dt}\right.$ and of thermal expansion coefficient $(\alpha)$ were recorded by DIL, as shown in Fig. 5.

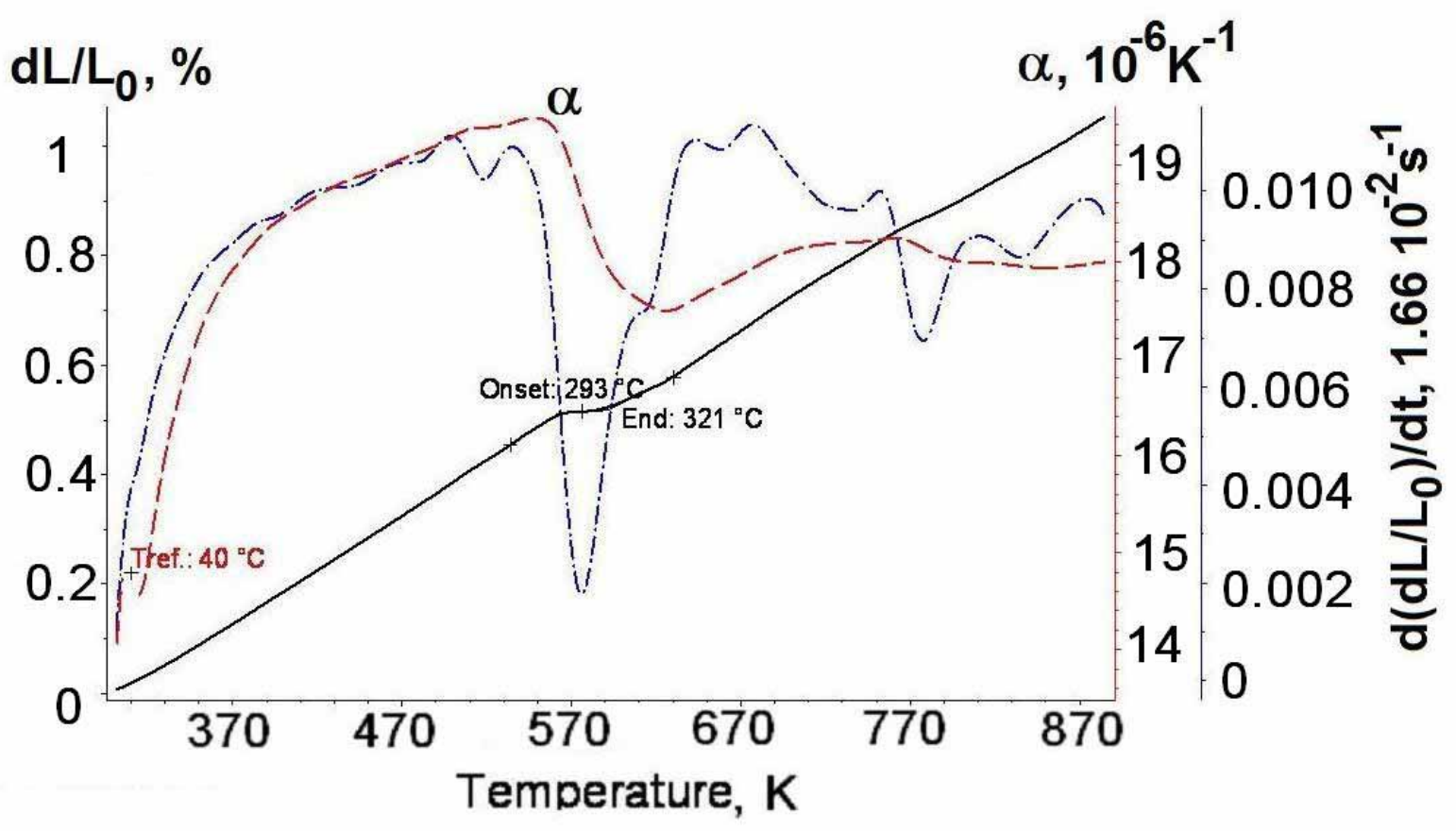

Fig. 5 DIL variations with temperature of relative elongation $\left(\mathrm{dL} / \mathrm{L}_{0}\right.$, solid line), of expansion rate $\left(\mathrm{d}\left(\mathrm{dL} / \mathrm{L}_{0}\right.\right.$, dot line $) / \mathrm{dt}$ and of thermal expansion coefficient ( $\alpha$, dashed line) of hot rolled solution annealed Cu-9.23 Al-5.3 Mn-0.6 Fe (mass, \%) SMA trained by 5 mechanical cycles up to $12 \%$

In case of DIL measurements, even if they are a little lifted to higher temperatures, the two above mentioned transitions are noticeable especially in the variation of expansion rate, where a marked decrease appeared followed by a two step increase, but also in the variation of thermal expansion coefficient which experiences a marked decrease.

Finally, some details regarding the morphology of stress induced martensite, in trained specimens subjected to five mechanical cycles up to $12 \%$, are offered by the SEM micrographs shown in Fig.6.

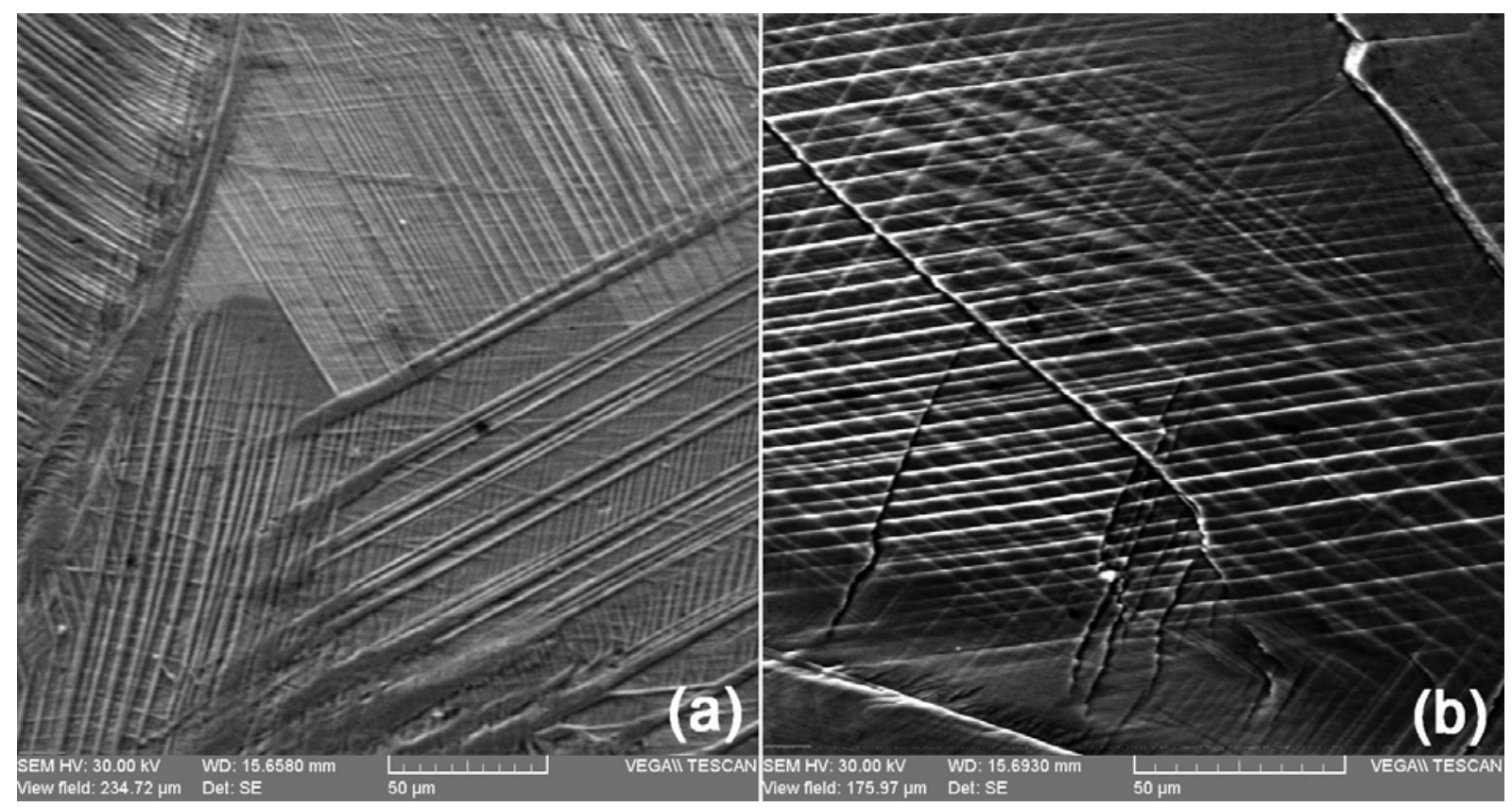

Fig. 6 SEM micrographs of hot rolled solution annealed $\mathrm{Cu}-9.23$ Al-5.3 Mn-0.6 Fe (mass, \%) SMA trained by 5 mechanical cycles up to $12 \%$ : (a) area with two martensitic morphologies; (b) area with martensite plates and cracks

Fig. 6(a) reveals an area with two martensitic morphologies, with large twinned plates and with very fine twinned plates, respectively [17]. The reversion to austenite, during heating, of these two "populations" of 
martensite plates, could correspond to the two step transition noticed by DMA and DIL. Fig. 6(b) shows the fact that martensite plates were formed prior to cracks, otherwise they would not be able to cross them. In addition, crack formation sheared some of the stress induced martensite plates causing small displacements between separated fragments.

\section{Conclusions}

The structure of a Cu-9.23 Al-5.3 Mn-0.6 Fe (mass, \%) SMA in hot rolled homogenization annealed condition din not reveal any evidence for the formation of thermally induced martensite as an effect of post homogenization water cooling, probably because $\mathrm{M}_{\mathrm{s}}$ critical temperature has been too low. For this reason, the alloy has been fully austenitic at RT and experienced ductile tensile behaviour during failure tests and pseudoelastic behaviour during loading-unloading tests. The former was characterized by ultimate strains above $40 \%$ and tensile strength about $800 \mathrm{MPa}$ while the latter occurred after 5 training cycles, when almost perfect superelasticity was obtained being characterized by typical recoverable strains above $4 \%$ and remanent strains less than $0.15 \%$ per cycle.

As an effect of permanent strain, accumulated during training cycles, stress induced martensite was formed, as revealed by OM and SEM. Since two martensite morphologies were noticeable [17] the two step solid state transitions observed by DMA and DIL were associated with the successive thermally induced reversions to austenite of the two martensite populations.

Acknowledgements This work was financially supported by UEFISCU by means of the research grant PN II-ID 616-PCE2007-1, contract no.83/01.10.2007. Special thanks are brought to Dr. Marcus Meyer for the support in calorimetric, internal friction and dilatometric measurements.

\section{References}

[1] C.M. Wayman, T.W. Duerig, ,An introduction to martensite and shape memory”, Engineering Aspects of Shape Memory Alloys, editors T.W. Duerig, K.N. Melton, D. Stöckel, C.M. Wayman, (ButterworthHeinemann, New York, 1990), p. 3

[2] M. H Wu, "Cu- based shape memory alloys", ", Engineering Aspects of Shape Memory Alloys, editors T.W. Duerig, K.N. Melton, D. Stöckel, C.M. Wayman, (Butterworth-Heinemann, New York, 1990), p. 69.

[3] T. Tadaki, "Cu-based shape memory alloys", Shape Memory Materials, editors K. Otsuka, C.M. Wayman, (Cambridge University Press, 1998), p. 97

[4] D. Reynaerts, H.Van Brussel, J Phys IV, III, Vol. 1, novembre, C4-157 (1991)

[5] Y. Sutou, T. Omori, R. Kainuma, N. Ono, K. Ishida, Metall. Mater. Trans. A, 33(September), 2817, (2002)

[6] H.L. Lukas, "Al-Cu-Mn" Ternary Alloy Systems. Phase Diagrams, Crystallographic and Thermodynamic Data”, editor G. Effenbeg, (Springer, 2005), p. 79

[7] V.V. Kokorin, L.E. Kozlova, A.O. Perekos, Mater Sci Eng. A 481-482 542 (2008)

[8] P. Villars, A. Prince, H. Okamoto, Handbook of Ternary Alloy Phase Diagrams, Vol. 3, (ASM International, 1995) p. 3297.

[9] S. Miyazachi, "Development and characterization of shape memory alloys", Shape Memory Alloys, editors M. Frémond, S. Miyazachi, (CISM Courses and Lectures, Springer, Wien-New York, 1996), p. 72

[10] S. Stanciu, L.G. Bujoreanu, Mat. Sci. Eng. A 481-482, 494 (2008).

[11] S. Stanciu, L.G. Bujoreanu, B. Özkal, M.L. Öveçoğlu, A.V. Sandu, J. Optoelectron. Adv. Mater., 10(6), 1365 (2008)

[12] S. Stanciu, L.G. Bujoreanu, I. Ioniță, A.V. Sandu, A. Enache, „A structural-morphological study of a $\mathrm{Cu}_{63} \mathrm{Al}_{26} \mathrm{Mn}_{11}$ shape memory alloy", Advanced Topics of Optoelectronics. Microelectronics and Nanotechnologies, edited by P. Schiopu, C. Panait, G. Caruntu, A. Manea, (Proc SPIE 7297, Bellingham, WA, 2009) p. 72970C

[13] L. G. Bujoreanu, S. Stanciu, B. Özkal, R. I. Comăneci, M. Mayer, J Mater Eng Perform, 18(5) August (2009) DOI: 10.1007/s11665-009-9499-2

[14] J. Spielfeld, Mat. Sci. Eng. A 273-275, 639 (1999).

[15] M. A. Morris, T. Lipe, Acta Metall. Mater. 42(5), 1583 (1994)

[16] U.S. Malik, V. Sampath, J Allyos Compd 469 (1-2) 156 (2009)

[17] J. Dutkiewicz, E. Cesari, C. Segui, J. Pons, J Phys IV, III, Vol. 1, novembre, C4-229 (1991) 